\title{
IDENTIDADES NARRATIVAS: \\ CONSTRUINDO SENTIDOS NA TRAVESSIA DA JUVENTUDE
}

\author{
Mirela Figueiredo Iriart ${ }^{I}{ }^{\star}$, Ana Cecillia de Sousa Bastos ${ }^{I I}$ \\ ${ }^{I}$ Universidade Estadual de Feira de Santana, Feira de Santana, BA, Brasil

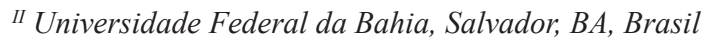

\begin{abstract}
RESUMo
Baseado nas perspectivas semiótica e sistêmica e na abordagem dialógica do desenvolvimento humano, este estudo teve como objetivo compreender as configurações do self, ao longo de trajetórias desenvolvimentais de jovens, vivendo em condição de vulnerabilidade social. $O$ self é entendido através da construção narrativa, como resultado da negociação de significados interpessoais e intrapessoais, dialogicamente, ao longo do tempo e do espaço. Três entrevistas narrativas com jovens, em diferentes contextos de formação (ONG, grupo de capoeira, Centro Sócio Educativo) na cidade de Salvador-BA foram selecionadas como casos exemplares. A partir de encontros com outros significativos e através da mobilidade das redes de significação, ao longo das transições desenvolvimentais, as narrativas dos jovens apontaram para possibilidades de ressignificação de eventos críticos e para a construção de novidade psicológica. Concluiuse que através da experiência narrativa foi possivel negociar as I-positions, reconfigurando o self dialogicamente e ampliando as perspectivas de futuro.
\end{abstract}

Palavras-chave: trajetórias de desenvolvimento; identidades narrativas; encontros significativos.

\section{NARRATIVe IDENTITIEs:}

\section{CONSTRUCTING MEANINGS TROUGH YOUTH TRANSITIONS}

\begin{abstract}
Based on the semiotic and systemic perspectives and on the dialogical self approach, this paper analyzes the self configuration, through the developmental trajectories of young people living in social vulnerability conditions. The self is understood through narrative construction, as forms of negotiating interpersonal and intrapersonal meanings, dialogically, over time and space. Three narrative interviews with young people in different contexts of Salvador-Bahia, (NGO, Capoeira group and Socioeducative centre for adolescents in law conflict) were analyzed. The mobility of the network of meanings, configured through meetings with significant others provide re-signification of critical experience and the

\footnotetext{
^ Endereço para correspondência: Universidade Estadual de Feira de Santana, Pós-Graduação em Educação - Avenida Transnordestina, s/n, Novo Horizonte. CEP: 44.036-900. Feira de Santana Bahia-Brasil.E-mail: mifis36@gmail.com, anaceciliabastos@gmail.com
} 
emergence of psychological novelty. The conclusions highlight the possibility of negotiating I-positions through the experience of narrating life trajectories, reconfiguring the self in a dialogical way and strengthening future expectations.

Keywords: developmental trajectory; narrative identities; significant meetings.

\section{INTRODUÇÃO: AS PERSPECTIVAS SEMIÓTICA E SISTÊMICA DO DESENVOLVIMENTO HUMANO}

Partindo-se da compreensão da natureza semiótica e sistêmica do desenvolvimento humano, em suas múltiplas dimensões espacial (macro e microsistêmica), relacional (pessoal e interpessoal) e temporal (presente, vivido, prospectivo), de maneira inclusiva, define-se o desenvolvimento humano como um sistema interativo aberto e dinâmico, que se reorganiza ao longo do tempo.

O modelo bioecológico/socioecológico compreende o desenvolvimento humano como um processo dinâmico e contínuo de interações bidirecionais entre a pessoa - considerando suas características biológicas, psicológicas e sociais - e o contexto sociocultural, como uma função articulada de (a) processos proximais; (b) estabilidade ao longo do tempo; (c) contexto ambiental em que elas ocorrem e (d) características das pessoas envolvidas (BRONFENBRENNER; CECI, 1994). Entende-se o contexto em seus diferentes níveis hierárquicos (micro, meso, exo e macrosistêmico), e as trajetórias de desenvolvimento, como mudanças bidirecionais pessoa/contexto, envolvendo rupturas, transições e redirecionamentos, mediadas semioticamente. O potencial desenvolvimental é intensificado em função do número de ambientes, estruturalmente distintos, em que o sujeito em desenvolvimento se engaja e na medida em que favoreçam a atividade conjunta, a confiança mútua e o consenso entre objetivos.

As trajetórias de desenvolvimento são processos de ajuste bidirecionais, ocorridos de forma não-linear, imprevisíveis e irreversíveis no tempo. As regularidades são construídas sobre a base de modificações constantes, operadas nas transações sociais, como fruto da tensão entre demandas e características pessoais e o mundo cultural de referência.

Assume-se, assim uma postura relativista e pluralista, buscando compreender as diferenças desenvolvimentais em relação ao conjunto de valores, costumes, crenças e práticas culturais e às diferentes possibilidades de inserção, de deslocamento e de mobilidade social dos sujeitos.

As múltiplas e complexas interações entre fatores como: potencial genético, habilidades e demandas pessoais, mais o contexto sociocultural de referência podem delinear caminhos prováveis e improváveis na trajetória de desenvolvimento de uma pessoa, canalizando o desenvolvimento em algumas direções e o distanciando de outras.

Consoante com a proposta da Rede de Significações (ROSSETI-FERREIRA et. al., 2004), compreende-se o desenvolvimento humano como um processo semiótico, integrando de forma dialética, diferentes dimensões da pessoa e do 
contexto num processo dinâmico que se configura enquanto rede. A configuração da rede circunscreve um conjunto de elementos que canalizam o desenvolvimento para algumas direções. Esses elementos, denominados de circunscritores, são tanto de ordem material como simbólica, e se constroem e reconstroem sob a influência de diversos fatores situacionais e interativos, pessoais e sociais, continuamente em movimento (SILVA; ROSSETI-FERREIRA; CARVALHO, 2004).

A compreensão da natureza dialógica do self surge como um ponto de virada teórico importante, como forma de perceber os processos desenvolvimentais, ao longo do tempo e do espaço, no movimento de vir-a-ser do sujeito, negociando sentidos nas interações com o outro, de forma dinâmica e relacional. Compartilha-se, então, de uma visão do self como uma construção semiótico-reflexiva, que procura manter a estabilidade ao longo do tempo, ao mesmo tempo em que lida com as novidades continuamente construídas, buscando a auto-regulação. Nesta direção, o desenvolvimento envolve processos de continuidade e de mudança, em que o self se movimenta entre a inovação e a auto-regulação.

Valsiner (2002) assinala a heterogeneidade do self como um conjunto de vozes (multivocalidade) em diálogo (auto-dialógico, como heterodialógico), operando como um catalizador na síntese de novas posições, a partir da relação entre suas partes (antagonismo, simultaneidade, apropriação), buscando uma integração (auto-organização).

A dinâmica do self, envolve posicionar-se e reposicionar-se no espaço e no tempo, nas tensões entre o "aqui-e-agora" e o "lá-e-então", entre o real e o imaginário; o presente e o futuro. Ao narrar a si mesmo, o sujeito pode conter as incertezas do futuro, ressignificar os eventos críticos do passado e reorganizar suas experiências no presente, a partir da incorporação de novidade ao sistema dialógico.

Na perspectiva narrativista de Bruner (1997) pode-se assumir a ideia de um self narrador, apontando para o caráter transitório, contextual e relacional da pessoa. $\mathrm{O}$ autor, ao enfatizar a centralidade das relações sociais e da linguagem nos processos de constituição da pessoa e da construção do sentido de si mesma, opõe-se a um modelo essencialista do eu.

Cada pessoa é múltipla, na heterogeneidade de vozes e posições que a cercam e "ao mesmo tempo preservam a abertura para a inovação e para a construção de novos posicionamentos e processos de significação acerca do mundo, do outro e de si mesma" (ROSSETI-FERREIRA et al., 2004, p. 27). Compreende-se o processo de desenvolvimento como a capacidade de ressignificação, de criação de novas formas de identificação, posicionamento e papéis, salientando-se o papel ativo dos sujeitos no seu agenciamento. A emergência de novidade psicológica é tanto um produto, como produtora do desenvolvimento.

Na perspectiva dialógica, a primazia da interação eu e Outro e das interações comunicativas é a base do desenvolvimento humano, evocando-se ainda a multivocalidade das interações dialógicas de inspiração baktiniana como um princípio da intersubjetividade. 
Incorporando às primeiras formulações da perspectiva do self dialógico (HERMANS, 1999, 2001) as novas contribuições de autores do eixo europeu, desenvolvidas em pesquisas clínicas e sociais, assume-se aqui: uma visão do eu como agente ativo na relação com o outro; a relação self-ambiente como um sistema dialógico aberto e regulado semioticamente; a compreensão das rupturas e transições na dinâmica desenvolvimental e da emergência do novo como projeção de novas I-positions no tempo. (BERTAU; GONÇALVES, 2007; ZITTOUN, 2008, CUNHA; GONÇALVES, 2009; O'SULLIVAN-LAGO; ABREU, 2010).

A multiplicidade de posições do self (I-positions) envolve processos de negociação em relações de conflito, ambivalência, dominação, tendo como resultado uma estruturação dinâmica que permita certa estabilidade e autonomia (agency) ao self. Como propõe Cunha (2007), através da análise microgenética, é preciso compreender como nos reconhecemos como nós mesmos, apesar da multiplicidade das experiências internalizadas, ao longo dos processos de subjetivação, nos diálogos com o outro e as possibilidades de inovação e de autorregulação que daí emergem.

Neste trabalho serão analisadas as transições desenvolvimentais e as reconfigurações do self, ao longo de trajetórias de jovens construídas sobre experiências críticas, movendo-se entre circunstâncias de risco e de proteção, ao responderem a alguns desafios tais como: desigualdades sociais, falta de qualificação profissional, escolarização deficiente, precárias estruturas de lazer e diferenças de acessibilidade aos serviços públicos. Discutir-se-á como, através das narrativas, os sujeitos vão negociando diferentes posicionamentos (I-positions), no encontro dialógico entre eu e o outro, no diálogo entre as vozes sociais e a vozes interiores (desejos e valores internalizados) na reconfiguração do self.

\section{Percursos, trajetórias e trajectividades na travessia da JUVEntude}

A concepção predominante de juventude, como analisa Abramo (1997), é de um importante momento de transição, "momento crucial no qual o indivíduo se prepara para se constituir plenamente como sujeito social", integrando-se à sociedade através da assunção de novos papéis, numa visão claramente normativa e linear das transições desenvolvimentais. A essa ideia acrescenta-se a de moratória social, momento em que os jovens estão sob a tutela do adulto, aguardando que a sociedade os reconheça e os autorize a produzir, amar e realizar seus desejos (CALLIGARIS, 2000). Estas duas ideias associadas à juventude, tanto nos discursos como nas práticas sociais, estão predominantemente marcadas por significados que desqualificam os jovens, não os incorporando na dinâmica social como construtores e dinamizadores culturais, capazes de contribuir na construção de repostas para suas próprias demandas.

Margulis (2001) salienta a necessidade de se reconhecer a juventude como uma categoria relacional: social, intergeracional e interpessoal, cuja base material é a idade, processada pela cultura - enquanto sistemas de significação - a depender do grupo cultural de referência, da posição social, do tipo de inserção na família, do gênero, compondo um panorama pluralista do que se caracterizaria como uma identidade juvenil. 
Ao refletir sobre o conceito de moratória social, Margulis (2001) argumenta que quando aplicado aos dias atuais ganha outros sentidos e passa a significar um tempo vazio, livre e ocioso, resultado do desemprego, da não inserção, do não lugar social, da exclusão e do desperdício do potencial do jovem. Para os jovens das classes populares brasileiras pode significar tempo de estarem na rua, fora de casa, fora da escola, fora do mundo do trabalho, espaços de construção de identidades inclusivas.

Concepções naturalizantes, descontextualizadas e normativas precisam ser problematizadas, como sistematizou Oliveira (2006), ao confrontar a perspectiva desenvolvimental tradicional, que comumente caracteriza a adolescência como momento de passagem e transição linear para a vida adulta, com as perspectivas de abordagem narrativista e dialógica.

Oliveira (2006) discute a necessidade de ultrapassar o modelo de subjetividade autocentrada para alcançar uma abordagem mais coerente com as demandas da contemporaneidade, que levem em conta o contexto intersubjetivo das práticas culturais, da linguagem como organizadora da subjetividade, através dos processos de internalização e externalização da cultura, na compreensão da relação entre desenvolvimento, identidade e narrativa.

O sujeito se define pela ação, o que significa opor uma visão "desengajada" de self ou de uma subjetividade interna, em direção a uma visão dialógica, onde o sujeito constrói sua subjetividade ao se dar a conhecer e conhecer-se, agindo no mundo, transformando-o, como co-participante de uma rede de relações sociais, por meio da linguagem (OLIVEIRA, 2003).

As ações ganham sentidos dentro de um contexto, mediadas pelo sistema de crenças, valores e significados. É do encontro/confronto com diferentes perspectivas, que os jovens, ao expandirem seus espaços e interações sociais, entram em contato com o novo, movendo-se em direção a sua individualização e autoconsciência. As interações e a participação social são fundamentais nesta construção.

A expansão dos espaços de participação envolve transições do centro para a periferia, das relações mais íntimas e diretas na família, para a vizinhança, a escola, o grupo de amigos, até a conquista dos espaços sociais mais periféricos, onde as relações são esporádicas e menos pessoais. Estas seriam transições graduais ao longo do processo de desenvolvimento, que garantiriam independência, aquisição de novos papéis e responsabilidades e ampliação da capacidade de negociação, delimitadas por fatores sócio-histórico-culturais (JANS, 2004).

Pais (1996) analisou formas de sociabilidades específicas dos jovens, as quais denominou de culturas juvenis, procurando entender a relação entre as trajetórias individuais e os contextos de socialização, enquanto condições sociais e geracionais, e os processos de transição do jovem, como processos de negociação complexos que se desenvolvem num campo simbólico de relações interindividuais, a partir do qual atribuem múltiplos significados à realidade. 
Os conceitos de trajetória e projeto de vida articulam-se com a ideia de tempo como categoria social, histórica e pessoal, compondo um horizonte temporal a partir do qual os jovens se situam em relação ao presente e ao futuro. Este horizonte enquadra um conjunto de escolhas ou alternativas possíveis, associados a diferentes campos de possibilidades, experiências de passado e expectativas de futuro que mediatizam a experiência vivida.

As trajetórias de vida - ao mesmo tempo sociais e individuais - encontram-se condicionadas por "trajetórias biográficas" estruturadas por "um conjunto de relações sociais e de identidades referidas a um dado contexto social: a família, a escola, o grupo de amigos, a comunidade de origem" (PAIS, 1996, p. 196). Estes contextos são unidades de transmissão cultural, campos semânticos que se interpenetram na estruturação dos múltiplos princípios de identificação e de reconhecimento social, formando o que o autor denomina de "bússolas cognitivas" dos indivíduos. É a partir destas pré-estruturações que os jovens escrevem os seus percursos, baseados nos mapas de significações que orientam suas escolhas sujeitas a processos constantes de organização e reorganização.

Leccardi (2005, p. 46) problematiza a ideia de projeto de vida, por conceber que há um esvaziamento da noção de futuro e uma centralidade da vivência de experiências no tempo presente " [...] como a única dimensão temporal disponível para a definição das escolhas, um verdadeiro horizonte existencial que, em certo sentido, inclui e substitui futuro e passado". Atualmente, na busca por dar sentido a suas existências, os jovens cada vez mais se utilizam de táticas de alcance mais imediato, em resposta à fragilização dos vínculos familiares, à precária inserção no mundo do trabalho, à fragilização de algumas redes de sociabilidade (vizinhança, vida comunitária) e das agências tradicionais de socialização (escola, família, igreja).

Em resposta a tal conjuntura de incertezas, os jovens lançam mão de estratégias de curto alcance, cujo manejo do tempo deve levar em conta a indeterminação carregada de potencialidade, agarrando-se às oportunidades do momento, substituindo projetos por objetivos. A trajetória biográfica, que se desdobraria em um projeto coletivo (familiar, geracional), tensiona-se com a ideia de um projeto individual, cuja ênfase na autodeterminação, nas escolhas pessoais e na autonomia do sujeito, coloca em xeque a capacidade de instituições como a família, a escola e o trabalho de ancoragem segura para as experiências juvenis. Logo, a ideia de transição, marcada pela linearidade do tempo, que normatiza o curso de vida, cede lugar a uma trajetória menos linear, que Pais (2006) chamou de "trajectividade", percurso sinuoso, construído nos intersticiais domínios da cultura, da sociabilidade, dos laços de amizade, "nos espaços lisos" - não formatados ou concedidos pelo adulto - onde podem expressar suas "performances juvenis" (hip hop, grafitismo, capoeira) deixando suas marcas como sujeitos sociais. 


\section{MÉTOdo: SUJEITOS, NARRATIVIDADE E TEMPORALIDADE}

A narrativa é um instrumento para organizar a experiência vivida por meio da linguagem. $\mathrm{O}$ caráter reflexivo da experiência humana, como um incessante fluxo entre passado, presente e futuro, coloca o indivíduo na posição de poder conceber seus modos de agir e ser, reavaliando e reformulando a cultura, como sujeito autônomo e posicionado historicamente. Neste sentido partilha-se da ideia de narrativa como ferramenta mental que faz a mediação entre o eu e o mundo, sentidos pessoais (identidades) e relações sociais, entre o mundo canônico da cultura e o mundo idiossincrático dos desejos, crenças e esperanças (BRUNER, 1997).

A narratividade oferece ao sujeito esta condição de autor, que constrói sua subjetividade agindo no mundo, transformando-o, como coparticipante de uma rede de relações sociais, por meio da linguagem (OLIVEIRA, 2003). Referenda-se, assim, "o pressuposto de que há uma dupla constituição entre sujeito e cultura, nos modos de subjetivação [...]" (OLIVEIRA; REGO; AQUINO, 2006, p. 122). As narrativas se materializam e ganham sentidos dentro de um contexto, mediadas pelo sistema de crenças, valores e significados, levando-se em conta, por exemplo, as repercussões das tensões sócio-históricas da contemporaneidade.

A etapa da pesquisa aqui descrita envolveu a seleção de três trajetórias de desenvolvimento, de 12 entrevistas narrativas realizadas com jovens entre 15 e 19 anos, em três diferentes contextos da adolescência, em 2003 e 2004: uma escola pública, num bairro periférico de uma grande cidade, uma ONG de referência no trabalho com arte-educação e cidadania e um centro socioeducativo para jovens em conflito coma lei (CASE), em regime de semi-liberdade. Procedeu-se a um recorte interpretativo das narrativas, a partir dos seguintes eixos temáticos: eventos críticos; Configurações do self(I-positions); orientação para o futuro

As entrevistas foram lidas a partir do modelo utilizado por Silva (2003), enquanto eventos narrados (histórias pessoais e coletivas contadas pelos sujeitos) e enquanto eventos narrativos (formas como o sujeito relata as experiências vividas), orientadas por um sentido de tempo e de espaço, por um enredo ou tema principal e secundário, composto por personagens e marcas da posição dos sujeitos no discurso.

As múltiplas dimensões temporais: tempo histórico (geracional e intergeracional); tempo vivido, o aqui-e-agora da interação; tempo presente, das experiencias vividas; e o futuro, enquanto expectativas e metas individuais e coletivas circunscrevem os processos desenvolvimentais em sua natureza dialética e dinâmica. O processo de análise envolveu recortes interpretativos do pesquisador, sobre o fluxo de eventos observados, alternando um olhar mais geral sobre o conjunto dos dados e um olhar mais minucioso sobre processos singulares, como sugerem Rosseti-Ferreira et al. (2004). 


\section{Resultados e Discussão}

\section{Trajetória de engajamento social}

Adolescente do sexo feminino, 18 anos, moradora de um bairro popular de Salvador, é a filha mais jovem e reside com mãe, pai e irmão. Possui três irmãos já casados. No momento estava se preparando para fazer vestibular, frequentava um cursinho preparatório e fazia um curso de Direitos Humanos, além de participar do grupo de poesia na ONG. Não possuía emprego, embora se sentisse pressionada para isto, pelo desejo de conquistar sua independência financeira e sair da casa dos pais. Novas relações de amizade são construídas a partir dos vínculos afetivos desenvolvidos na ONG, compartilhando espaços culturais "alternativos" da cidade, como a Biblioteca Pública do Estado e outros.

As mudanças que vinham se processando em seu modo de ser e estar no mundo, diziam respeito primeiramente a sua relação com a família e depois com o próprio bairro onde morava. Novos campos de significação foram construídos como fruto das novas interações, atividades e posicionamentos ativados desde que passou a se integrar aos projetos desenvolvidos na ONG. Posicionando-se como uma pessoa mais aberta e questionadora, que não aceita facilmente ser contrariada, vai se afirmando ao longo da narrativa como uma pessoa mais consciente dos seus desejos e objetivos futuros, muitas vezes contrariando a expectativa da família.

Na negociação entre as posições do self, em relação ao passado-presente, eu-outros, percebe-se a sua busca por autonomia e ao mesmo tempo a construção de sua diferenciação, em relação aos jovens da sua comunidade:

Lá no bairro eu só tenho uma amiga, que também é daqui [da ONG] [...] Eles não tiveram oportunidade, este lance da oportunidade mesmo, estão muito fechados num mundinho que só conhece pagode, drogas e sexo, só vivem neste mundo e não conhecem outras coisas.

A construção de novas identificações, a partir da convivência com "pessoas diferentes", modifica a percepção de si. Toma distância em relação ao seu lugar de origem, na medida em que passa a não se identificar mais com os jovens, de "lá" (do bairro onde mora), já que "eles não tiveram oportunidade", enquanto: "eu entrei no projeto", demarcando uma nova identificação e novo papel social.

Segundo ela, entrar para o grupo de poesia: "me ajudou a ser uma pessoa mais sociável, era muito fechada, eu era muito introspectiva, a estar me ligando mais, não viver só no meu mundo, a estar aberta, a enxergar melhor o mundo a minha volta".

A descontinuidade entre o "agora", confrontado a um "antes de", gera novas I-positions em desenvolvimento no presente, ("estou convivendo", "me identificando"), tendo como marco temporal a entrada no projeto. Ao mesmo tempo busca as regularidades do self ao utilizar o marcador temporal "sempre": "sempre quis fazer alguma coisa", o que a posiciona como alguém que busca realizar seus 
objetivos, superando dificuldades. Há um processo em andamento, algo que já se iniciou e se prolonga em direção ao futuro, do qual ela vai se dando conta ("fui percebendo que podia."), enquanto novas possibilidades se afirmam no presente ("estou conseguindo"). Novas sínteses são construídas do cruzamento das temporalidades e dos diferentes contextos em que transita, ampliando a rede de significações onde está imersa.

A narrativa constrói-se como um diálogo interno, em que a jovem busca ressignificar antigas posições, a partir de um evento crítico que afetou o microssistema familiar: envolvimento de um irmão com uso de drogas e violência no bairro, forçando-a a reavaliar suas atitudes e favorecendo a mobilidade das posições do self, num movimento de posicionamento e reposicionamento.

Tal evento, aliado à nova rede social que vem sendo construída, marcou a negociação entre as posições: introspectiva, sociável, com a emergência de novos sentidos de si, percebidos como uma "explosão" pela família e pelos amigos, personagens com os quais dialoga nas suas narrativas.

[...] aconteceram algumas coisas na minha vida, coisas ruins mesmo, que me fizeram mudar, que eu falei assim, se eu não mudar agora, eu não vou mudar mais, [...] Hoje em dia eu consigo falar, consigo escrever, mudou bastante. Minha família era muito complicada, aí aconteceram algumas coisas na família, eu via muitas coisas [Tipo o quê, violência?] É violência, irmão envolvido com drogas, aí como era uma pessoa introspectiva, eu sempre tentava resolver sozinha.

O diálogo entre as diferentes posições do self demonstra as múltiplas vozes do self negociadas (autodiálogo e heterodiálogo), na busca de novas sínteses (VALSINER, 2002).

A mudança partiu ainda de uma maior autoconsciência do seu isolamento, momento em que refere como uma fuga da realidade e de uma idealização do futuro, pela não aceitação do presente.

O horizonte temporal projeta-se em direção a objetivos futuros a partir das novas possibilidades de escolhas que surgem do seu engajamento social e de suas motivações para mudança: prestar vestibular para o curso de História, ter independência financeira, morar sozinha, e ainda ampliar seus contextos de participação social. Isto significa superar uma trajetória biográfica, no sentido de romper com as expectativas da família e até mesmo confrontar os lugares sociais predeterminados, como ser jovem, mulher e negra.

Pode-se sintetizar sua trajetória como de engajamento social, onde passa a exercer atividades no bairro e na cidade, através da poesia, gerando um maior reconhecimento de si no mundo, "jovem, mulher e negra", favorecendo a sua autoestima e autodirecionamento, mediada pelas estruturas de oportunidade que se abrem no contexto imediato da ONG, estendendo-se para o mesosistema (família, comunidade). 
O contexto grupal, espaço de compartilhamento e aprendizagem social que Eckert (1995) denomina de uma comunidade de prática (comunity of practice) ou ainda pensado como uma zona de contato cultural (cultural contact zone context,) na visão de O'Sullivan-Lago e Abreu (2010) - produz novidade psicológica, já que os sujeitos reorganizam as experiências do passado e projetam suas trajetórias futuras, mediadas pela relação institucional, através de discursos e práticas compartilhadas. Isto implica em novas formas de ação e de reconhecimento social, novos conhecimentos sobre si e sobre o mundo, habilidades comunicacionais e relacionais, que atualizam o potencial do sujeito e introduzem novas formas de identificação, integrando novas posições ao self.

\section{Trajetória de Profissionalização}

Adolescente do sexo masculino, 17 anos, morador do subúrbio de Salvador, estudante da 9.a série do ensino fundamental de uma escola pública do bairro, é o único filho homem, mora com a mãe e o pai, tem uma irmã mais velha, que teve uma filha ainda adolescente e que hoje moram com eles. O pai é pedreiro e não tem emprego fixo, a mãe estava desempregada, mas possuía uma barraca de doces na frente de casa. Pratica capoeira e participa de apresentações remuneradas em hotéis nos bairros nobres da cidade. Seu desejo é ser dançarino profissional e se apresentar no exterior.

Iniciou a entrevista falando da experiência de discriminação que caracteriza o viver num bairro de periferia, marcado pela violência, contrapondo em seguida o seu orgulho de ser morador do subúrbio pelas suas belezas naturais e por que, diferentemente de outros jovens, soube aproveitar as oportunidades e construir uma trajetória alternativa:

[...] a Suburbana, é fogo, o perigo aqui está pior [...] até amigos meus amigos, assim, pessoas que já estudavam comigo na infância, já morreram, têm muitos que já tá prestes a morrer, [...] eu falo: "pôxa, se tivesse um caminho igual ao meu?" "praticasse um esporte", alguma coisa assim, acho que não estaria nessa situação.

Ao comparar sua trajetória com a de alguns amigos que já morreram, ou estão jurados de morte, posiciona-se como alguém que ativamente conseguiu superar as dificuldades e construir um percurso, a partir das oportunidades acionadas no contexto comunitário, através de um encontro significativo com um professor de capoeira.

Relata o desenrolar da sua história a partir de um evento crítico que foi o desemprego da mãe, evento que marcou um ponto de virada (turning point) na sua trajetória, em direção à profissionalização. Ao buscar enfrentar as dificuldades, assume a posição de coprovedor da família, e vai ressignificando sua inserção no bairro, ao incorporar a identidade de professor de capoeira, alguém que pode repassar para outros jovens sua própria experiência. 
Quando minha mãe se desempregou eu tinha 13, 14 anos de idade, meu pai era pedreiro, sabe que pedreiro não tem assim trabalho fixo, aí eu tava vendo as coisas em casa, assim a situação não tava legal, aí eu comecei [...], entrei em curso de oficina mecânica, aí eu tomava curso de mecânica, depois saí da mecânica, fui vender peixe, saí vendendo peixe, frutos-do-mar, aí com 15 anos eu entrei na capoeira, onde eu estou até hoje.

A trajetória biográfica traz a marca de um ethos familiar, que funciona como uma moral, regulando as condutas cotidianas pela valorização do trabalho, da superação das dificuldades, configurando os circunscritores pessoais (self constraints), como uma bússola interna - na metáfora usada por Pais (1996) - que direciona suas escolhas, organiza suas ações e dá sentidos a sua vida.

Procura construir uma narrativa linear, apresentando as mudanças contínuas que reorientaram sua trajetória, centrada na prática da capoeira, habilidade que passa a reconhecer como um dom e que o reposiciona em relação a si mesmo e aos outros. Modifica sua maneira de ser e estar no mundo, ao assumir a identidade de artista, a partir da identificação com o grupo de capoeira, integrando-se a um coletivo: "a gente passa a trabalhar com artes [...], a gente toma um banho novo, muda", posicionando-se de forma mais autônoma e diferenciada, movendo-se através de novas redes de significações e deslocando-se nas malhas construídas do seu entrelaçamento, configurando campos de sentidos que convergem.

O encontro com o outro significativo - professor de capoeira - foi decisivo neste reposicionamento. Uma pessoa investida de afeto que ocupou o lugar de um segundo pai e lhe mostrou um caminho, segundo ele "o caminho certo", em comparação às trajetórias malsucedidas de alguns amigos seus. $\mathrm{O}$ caminho por onde a capoeira o levou significa não só uma oportunidade de profissionalização, mas também a construção de uma identidade positiva, que se expressa no seu maior reconhecimento social e respeito dentro da comunidade, aumentando seu sentido de pertencimento e ampliando sua mobilidade social por outros espaços para além da comunidade:

[...] eu tive, um grande apoio de meu professor, que ele é uma pessoa bem experiente, é de mais idade, né? Então, essa pessoa que eu digo assim, é um segundo pai para mim, porque o pouco que eu sei hoje, onde eu estou hoje, eu agradeço a essa pessoa que é tudo pra mim. O que eu fizer pra ele é pouco, entendeu? Essa pessoa me deu uma força, me deu, me mostrou o caminho certo.

O projeto de futuro se delineia a partir da necessidade de ajudar a família (dar uma casa para a mãe), objetivos que podem ser alcançados com a capoeira, através de apresentações do grupo, inclusive no exterior. Seu horizonte temporal 
envolve sair da comunidade, viver um tempo fora do Brasil, ganhar dinheiro e retornar. A ajuda de Deus e seu próprio empenho são elementos determinantes, que aparecem repetidos na narrativa, como forma de dar conta das incertezas.

Pode-se sintetizar sua narrativa como uma trajetória em direção à profissionalização, fortemente marcada pelo ethos familiar e pela presença do outro significativo, que lhe direcionou para novos caminhos a partir do qual ele construiu um autodirecionamento que lhe confere novos sentidos para a vida e lhe motiva a seguir uma trajetória alternativa, como superação dos obstáculos, agenciando seu próprio desenvolvimento.

\section{Trajetória de Circulação}

Jovem do sexo masculino, 16 anos, foi criado por uma tia até os 5 anos de idade, pois a mãe o abandonou e só voltou a procurá-lo aos 9 anos de idade. Saiu do interior com 7 anos e veio morar em Salvador, com uma irmã que até então não o conhecia. Aos 9 anos a mãe biológica o procurou e o levou para morar com ela. Aos 10 anos fugiu da casa da mãe, que segundo ele lhe batia sempre que bebia, e foi morar na rua, onde passou a praticar pequenos furtos. Pediu ajuda ao Juizado e foi levado para uma Casa de Convivência, onde passou aproximadamente um ano. Aos 11 anos foi levado por uma outra tia para morar com ela e aos 13 anos foi colocado para fora por que furtou dinheiro em casa. Depois de denunciado pela tia, foi levado pelo Juizado para o Centro de Apoio ao Menor (CAM), onde permaneceu durante 1 ano e 9 meses. Há 2 anos e meio aproximadamente estava frequentando a CASE, em regime semiaberto, onde fazia aulas de dança africana e de desenho. Cursava o 9.o ano do ensino fundamental e pensava em ser dançarino profissional. Poucas semanas depois da realização da entrevista, encontrava- se evadido da instituição.

Relata uma trajetória marcada pelas rupturas com os vínculos afetivos, desde o abandono da mãe quando ainda era bebê e a circulação por diferentes locais de moradia. Veio do interior, morou com duas tias, uma irmã, que até então não conhecia e desde os 10 anos de idade já passou por várias instituições. Sua narrativa é entrecortada por "aís": "aí fui morar", "aí fiquei”, "aí acabei indo", confirmando as sucessivas interrupções da sua trajetória, pelas sucessivas mudanças de casa e de pessoas com quem morou por curtos períodos, com quem não havia nenhum vínculo afetivo anterior. A falta de continuidade se expressa ainda na dificuldade de ajustamento a cada nova situação, marcada por adversidades como maus tratos e pela distância afetiva com o cuidador: primeiro uma tia distante, depois uma irmã que não o conhecia, depois a mãe a quem nunca reconheceu, depois outra tia e por fim o Juiz. O contexto institucional passa a significar contexto de proteção e uma estrutura de oportunidade no redirecionamento da sua trajetória de vida, como um ponto de ancoragem a partir do qual novas potencialidades se revelam, como assume:

[...] eu já roubei muito, apesar de que hoje em dia eu não roubo mais. Já andei com muitas pessoas que usavam drogas, que usam drogas até hoje, mas eu nunca usei, nunca me levei 
[...] Então, o mundo tá me dando muita oportunidade, os cursos que eu tô tendo, escola, viu?

O encontro com a instituição é visto como um ponto de virada na sua trajetória de risco, pela descoberta de uma capacidade até então desconhecida, o desenho e a dança, em meio à ausência de outras figuras de referência importantes em sua vida. Este momento de reflexão é o momento de afirmar um self em mudança, que quer vencer:

[...] eu não sabia que eu tinha o dom de desenhar. Aí teve um dia que a psicóloga chegou e perguntou pra mim se eu sabia desenhar e eu falei "não sei, eu nunca tentei” aí e eu fui treinando, desenhando, até que deu que eu tinha o dom de desenhar, de fazer qualquer coisa que eu quisesse, qualquer desenho que eu olhasse, eu poderia desenhar, ampliar.

A tomada de consciência de suas novas habilidades oferece uma constelação de novos significados que podem reconfigurar o self, fazendo emergir posições (figura) que antes não eram reconhecidas (fundo), a partir da motivação acionada pelo discurso da psicóloga, favorecendo um maior agenciamento da própria vida.

Sua narrativa, no entanto, segue uma estruturação ambígua, deslizando pelas posições de vitima, culpado e dependente da instituição. A ressignificação dos eventos críticos (roubos, detenções, perda de vínculos) não é fácil, pois o cristaliza em uma narrativa circular, presa aos "erros" do passado, enredando-o numa rede cuja centralidade está no abandono, preconceito e baixa auto-estima. Ao mesmo tempo é sobre o imperativo: "construir sozinho a minha vida, não depender de ninguém", que ele de fato vem conseguindo se sustentar no mundo, buscando redirecionar sua trajetória: [...] "porque desde quando minha tia me colocou de fora da minha casa, eu jurei pra mim mesmo que eu iria fazer minha vida, sozinho, ia construir minha vida, sozinho sem depender de ninguém”.

Percebe-se que a narrativa, construída para a pesquisadora, é também uma autonarrativa, como uma voz social que precisa ser internalizada para não desviá-lo dos seus objetivos, mostrando, ao mesmo tempo as fragilidades deste percurso, sem pontos de ancoragem que lhe forneçam referências mais seguras e autodireconamento suficientes para sustentar a emergência de novos posicionamentos (I-positions), reorganizando o self.

Bom, muitas pessoas acham que pessoas da FUNDAC (Fundação da Criança e do Adolescente), de instituição ou abrigo, quando sair daqui não vai ter, digamos assim, é, não vai ter uma trajetória boa, não vai ter uma vida digna, assim, mas eles tão enganado, viu, quando eu sair daqui eu tenho certeza de que eu vou ter minha própria vida. Minha vida vai ser uma vida normal como cidadão. 
As posições ambíguas presentes neste heterodiálogo e autodiálogo, não favorecem que o sistema desenvolvimental avance significativamente, demonstrando sua labilidade social quando evade da instituição mais uma vez, poucos dias depois da entrevista, levando o gravador que tomou emprestado da pesquisadora.

A circularidade parece ser uma constante na sua trajetória, caracterizada por contínua fragmentação dos vínculos afetivos e sociais, contada ao longo de uma narrativa, onde se observa uma flutuação das posições do self e uma alienação de si, mantendo o sistema num padrão de repetição ao longo do tempo (RIBEIRO; GONÇALVES, 2010).

\section{Considerações Finais}

As três trajetórias se tocam, ou se cruzam em alguns pontos, quando se observam as incertezas quanto ao futuro, a dificuldade de inserção social, ao lado da superação de desafios pelas novas possibilidades de ação e posicionamentos ativados a partir das estruturas de oportunidades e dos encontros significativos. As redes de significação que vão circunscrevendo novos campos de sentidos, apropriados pelos sujeitos, ampliam o seu repertório de I-positions e a dialogicidade do self. A busca de estabilidade do sistema, nem sempre significa um processo desenvolvimental, quando diante das ambiguidades, o self se mantém cristalizado através de narrativas cíclicas, não atingindo níveis mais complexos de organização. Nas tentativas de produzir sentidos para si, faz-se necessário reconhecer o sistema de valores e motivações e os vínculos afetivos que podem ativar o agenciamento do sujeito.

Numa análise sistêmica, pode-se considerar a importância das transições - através dos diversos níveis do contexto - na reconfiguração dos elementos materiais, sociais e simbólicos, favorecendo resultados desenvolvimentais quando possibilitam a complexificação de processos proximais: incorporação de novos papéis; reconfiguração de significados; ampliação das interações sociais ; construção de novos vínculos socioafetivos.

No nível do mesossistema, da relação entre escola e família, do projeto social com a comunidade, ou ainda do centro de atendimento socioeducativo com a escola e a família, observaram-se dificuldades e obstáculos de ação conjunta e intercâmbio. A ausência da família, no caso do jovem em situação de semi-liberdade, ou a falta de articulação e organização comunitária, no caso da jovem que frequenta o projeto social, ou a pouca abertura da escola na comunicação com a família e com a comunidade, mostram a fragilidade entre os nós das redes, por onde os sujeitos poderiam se deslocar, dificultando a ampliação de recursos desenvolvimentais, tais como mecanismos de participação e inserção sócio-profissional, por exemplo.

Ao se olhar para o macrosistema, enquanto práticas institucionais discursivas e não discursivas, observam-se obstáculos que restringem a mobilidade social dos jovens, frustrando expectativas e fragmentando as ações institucionais, que não encontram uma continuidade entre os níveis do sistema. 
É possível perceber que a construção das narrativas pressupõe o diálogo com o outro, buscando nas diferenças e semelhanças, as regularidades de si, com base na dialogicidade entre o eu e o não eu; entre o eu e o mundo, na negociação entre o aqui-e-agora e "o lá e então", projetando-se a si no movimento temporal do "como é", para o "como si". É a possibilidade de agir, criar e se modificar, que confere ao sujeito o agenciamento sobre o seu desenvolvimento, na busca por uma estabilidade dinâmica do self.

A dialética indivíduo-contexto-tempo, mostrou-se uma unidade desenvolvimental relevante, ao se analisar os diferentes percursos dos jovens, movendo-se e posicionando-se discursivamente através da rede de significações, ao configurar campos de sentidos múltiplos e interligados, compondo uma "malha" ou tecido, mediando semioticamente as experiências no presente e as projeções do futuro. Os encontros significativos criaram oportunidades através das quais os jovens puderam atualizar seu potencial desenvolvimental, ampliar o repertório comportamental e motivacional e redirecionarem suas trajetórias de vida.

A partir de cada discurso, das vozes jovens aqui reunidas, colocam-se desafios institucionais, políticos e sociais, ao se olhar para os jovens e enxergá-los como participantes ativos na construção da cultura, com enorme potencial de criação e de mudança no presente. Considera-se ainda a importância dos pontos de ancoragem que favoreçam os processos de subjetivação, numa sociedade em que se vive uma fragmentação das instituições tradicionais e uma fluidez dos afetos e das formas de pertencimento, na travessia da juventude. 


\section{REFERÊNCIAS}

ABRAMO, H. Considerações sobre a Tematização Social da Juventude no Brasil. Rev. Bras. Educ. Rio de Janeiro, n. 05-06, p. 25-36, maio/dez. 1997.

BERTAU, M. C; GONÇALVES, M. Looking at "meaning as movement" in development: introductory reflections on the developmental origins of the dialogical self. International Journal for Dialogical Science, Holanda, v. 2, n. 1, p. 1-13, 2007.

BRONFENBRENNER, U.; CECI, S. J. Nature-Nurture reconceptualized: a bioecological model. Psycholoical Review, Washington D.C., v. 101, n. 4, p. 568586, out. 1994.

BRUNER, J. Atos de Significação. Porto Alegre: ArteMed, 1997.

CALligaris, C. A Adolescência. São Paulo: Publifolha, 2000. Série Folha Explica.

ECKERT, P. Trajectory and forms of institutional participation. In: CROCKET, L.; CROUTER, A. Pathways through adolescence: individual development in relation to social contexts. New Jersey: Lawrence Erlbaum Associates, 1995. p. 175-196.

CUNHA, C. Constructing organization through multiplicity: a microgenetic analysis of self-organization in the dialogical self. International Journal for Dialogical Science, Holanda, [S.1.], v. 2, n. 1, p. 287-316, 2007.

CUNHA, C.; GONÇALVES, M. Accessing the experience of a dialogical self: some needs and concerns. Culture \& Psychology, [S.1.], v. 15, n. 1, p. 120-133, Mar. 2009.

HERMANS, H. J. M. Dialogical thinking and self-innovation. Culture \& Psychology, [S.1.], v. 5, n. 1, p. 67-87, Mar. 1999.

HERMANS, H. J. M. The dialogical self: toward a theory of personal and cultural positioning. Culture \& Psychology, [S.1.], v. 7, n. 3, p. 243-281, Sept. 2001.

JANS, M. Children as citizens: towards a contemporary notion of child participation. Childhood, [S.1.], v. 11, n. 1, p. 27-44, 2004.

LECCARDI, C. Por um novo significado do futuro: mudança social, jovens e tempo. Tempo Social. São Paulo, v. 17, n. 2, p. 35-57, 2005.

MARGULIS, M. Juventud: una aproximación conceptual. In: BURAK, S. (Org.). Adolescencia e juventud en América Latina. Cartago: Libro Universitário Regional, 2001. p. 43-55. 
OLIVEIRA, M. C. Subjetividade e conhecimento: do sujeito da representação ao sujeito dialógico. Revista do Departamento de Psicologia - UFF, Niterói, v. 15, n. 1, p. 33-52, jan./jun. 2003.

OLIVEIRA, M. C. Identidade, narrativa e desenvolvimento na adolescência: uma revisão crítica. Psicologia em Estudo, Maringá, v. 11, n. 2, p. 427-436, maio/ago. 2006.

OLIVEIRA, M. K.; REGO; T. C.; AQUINO, J. G. Desenvolvimento psicológico e constituição de subjetividades: ciclos de vida, narrativas autobiográficas e tensões da contemporaneidade. Pro-Posições, Campinas, v. 17, n. 2 (50), maio/ ago. 2006. p. 119-138.

O'SULLIVAN-LAGO, R; ABREU, G. Maintaining continuity in a cultural contact zone: identification strategies in the dialogical self. Culture Psychology, [S.1.], v. 16, n. 1, p. 73-92, 2010.

PAIS, J. M. Culturas Juvenis. Lisboa: Imprensa Nacional Casa da Moeda, 1996

PAIS, J. M. Buscas de si: expressividades e identidades juvenis. In: ALMEIDA, M. I. M. de; EUGÊNIO, F. (Org.). Culturas Jovens: novos mapas do afeto. Rio de Janeiro: Zahar, 2006. p.7-21.

RIBEIRO, A. P.; GONÇALVES, M. Innovation and stability within the dialogical self: the centrality of ambivalence. Cultural \& Psychology, [S.1.], v. 16, n. 1, p. 116-126, 2010.

ROSSETI-FERREIRA, M. C. et al. Redes de significações e o estudo do Desenvolvimento Humano. Porto Alegre: ArteMed, 2004.

SILVA, A. P. S. (Des) continuidades no envolvimento com o crime: construção de identidade narrativa de ex-infratores. São Paulo: IBCCRIM, 2003.

SILVA; A. P.; ROSSETI-FERREIRA, C.; CARVALHO, A. M. Circunscritores: limites e possibilidades no desenvolvimento. In: ROSSETI-FERREIRA, M. C. et al. (Org.). Redes de significações e o estudo do Desenvolvimento Humano. Porto Alegre: Artemed, 2004. p. 81-92.

VALSINER, J. Forms of dialogical relations and semiotic autoregulation within the self. Theory and Psychology, Satandford, v. 12, n. 2, p. 251-265, 2002.

ZITTOUN, Z. Sing the gap: dialogical self in disrupted times. Studia Psychologica, Porto, v. 6, n. 8, p. 73-89, 2008.

Recebido em: 27 de abril de 2011

Aceito em: 05 de junho de 2013 
